\title{
Macro/microporous silk fibroin scaffolds with potential for articular cartilage and meniscus tissue engineering applications
}

\author{
4 Q1 Le-Ping Yan ${ }^{a, b}$, Joaquim M. Oliveira ${ }^{a, b}$, Ana L. Oliveira ${ }^{a, b, c}$, Sofia G. Caridade ${ }^{a, b}$, João F. Mano ${ }^{a, b}$, \\ 5 Rui L. Reis ${ }^{\mathrm{a}, \mathrm{b}, *}$ \\ a 3B's Research Group - Biomaterials, Biodegradables and Biomimetics, University of Minho, Headquarters of the European Institute of Excellence on Tissue Engineering \\ and Regenerative Medicine, AvePark, S. Cláudio de Barco, 4806-909 Taipas, Guimarães, Portugal \\ b ICVS/3B's - PT Government Associate Laboratory, Braga/Guimarães, Portugal \\ ${ }^{\mathrm{c}}$ Department of Health Sciences, Portuguese Catholic University, 3504-505 Viseu, Portugal
}

\section{A R T I C L E I N F O}

\section{Article history:}

Received 21 June 2011

Received in revised form 30 September 2011

Accepted 30 September 2011

Available online $\mathrm{xxxx}$

\section{Keywords:}

Silk fibroin

Porous scaffold

Salt leaching

Articular cartilage

Meniscus

\begin{abstract}
A B S T R A C T
This study describes the developmental physicochemical properties of silk fibroin scaffolds derived from high-concentration aqueous silk fibroin solutions. The silk fibroin scaffolds were prepared with different initial concentrations $(8,10,12$ and $16 \%$, in wt.\%) and obtained by combining the salt-leaching and freezedrying methodologies. The results indicated that the antiparallel $\beta$-pleated sheet (silk-II) conformation was present in the silk fibroin scaffolds. All the scaffolds possessed a macro/microporous structure. Homogeneous porosity distribution was achieved in all the groups of samples. As the silk fibroin concentration increased from 8 to $16 \%$, the mean porosity decreased from $90.8 \pm 0.9$ to $79.8 \pm 0.3 \%$ and the mean interconnectivity decreased from $97.4 \pm 0.5$ to $92.3 \pm 1.3 \%$. The mechanical properties of the scaffolds exhibited concentration dependence. The dry state compressive modulus increased from $0.81 \pm 0.29$ to $15.14 \pm 1.70 \mathrm{MPa}$ and the wet state dynamic storage modulus increased by around 20 - to 30 -fold at each testing frequency when the silk fibroin concentration increased from 8 to $16 \%$. The water uptake ratio decreased with increasing silk fibroin concentration. The scaffolds present favorable stability as their structure integrity, morphology and mechanical properties were maintained after in vitro degradation for 30 days. Based on these results, the scaffolds developed in this study are proposed to be suitable for use in meniscus and cartilage tissue-engineered scaffolding.
\end{abstract}

(c) 2011 Acta Materialia Inc. Published by Elsevier Ltd. All rights reserved.

\section{Introduction}

The development of novel three-dimensional degradable porous scaffolds is of great interest for tissue engineering and regenerative medicine [1]. There are several critical requirements in the design and preparation of the scaffolds [2,3]. With these requirements in mind, different biomaterials have been explored as matrices to be used in tissue-engineered scaffolding, such as synthetic and naturally occurring polymers and bioactive calcium phosphate ceramics [4-10]. Among these, silk fibroin derived from the silkworm Bombyx mori has proved to be a promising candidate as a scaffolding material $[11,12]$. In vivo, its foreign body response is dependent on the implantation site and the model chosen; in most cases, the response is low and subsides with time [11]. Addition-

* Corresponding author at: 3B's Research Group - Biomaterials, Biodegradables and Biomimetics, University of Minho, Headquarters of the European Institute of Excellence on Tissue Engineering and Regenerative Medicine, AvePark, S. Cláudio de Barco, 4806-909 Taipas, Guimarães, Portugal. Tel.: +351 253510 900; fax: +351 253 510909.

E-mail address: rgreis@dep.uminho.pt (R.L. Reis). ally, it is a versatile material for tissue-engineered scaffolding as its degradability and mechanical properties can be tailored by chemical cross-linking or by the introduction of $\beta$-sheet conformation [13]. Moreover, it can be processed easily into various structures, such as fiber meshes, membranes, hydrogels, threedimensional porous scaffolds, and microspheres [14-21]. For the above reasons, silk-based scaffolds have been successfully applied in tissue engineering of skin, bone, cartilage, tendon and ligament $[11,12]$. These structures have produced favorable outcomes in previous biomedical explorations [22-26].

In order to produce porous silk fibroin scaffolds, a diversity of methods have been used, such as salt leaching, gas foaming, freeze-drying and rapid prototyping [14,19,26-28]. Kim et al. [14] proposed a new strategy to prepare porous silk fibroin scaffolds by means of using aqueous-derived silk fibroin solutions and the salt-leaching method. The whole preparation procedure was undertaken in an aqueous environment, and the scaffolds produced presented new features regarding the biodegradation and mechanical properties [14,17]. Makaya et al. [28] developed a modified method to prepare salt-leached silk fibroin scaffolds via a size-reduced porogen $(250-500 \mu \mathrm{m})$ for cartilage regeneration.

1742-7061/\$ - see front matter (c) 2011 Acta Materialia Inc. Published by Elsevier Ltd. All rights reserved. doi:10.1016/j.actbio.2011.09.037 
Wang et al. [29] further studied the synergistic effects of salt-leached silk fibroin and a hydrodynamic environment in cartilage tissue regeneration. However, to the authors' knowledge, salt-leached porous scaffolds prepared with more than $10 \%$ aqueous silk fibroin solution have not yet been reported [14,17]. Although there are a few reports about the use of high-concentration silk fibroin solution $[15,19,23,30,31]$, none of them involved processing routes to form different structures by comprising combination of salt-leaching and freeze-drying methodologies.

The previous studies indicated that the compressive modulus values of the salt-leached silk fibroin/cell constructs were still very low, although they were higher than the silk scaffold controls, as reported by Marolt et al. [32] and Kim et al. [33]. Preparing silk or silk-based scaffolds with initial improved mechanical properties for specific tissue engineering applications is of great interest $[34,35]$. In the present work, highly concentrated aqueous silk fibroin solutions were used to prepare silk-based scaffolds, with the aim of improving the obtained physicochemical properties. The mechanical properties and three-dimensional architecture were tailored to make them suitable for cartilage and meniscus tissue engineering. The aqueous-derived silk fibroin scaffolds were prepared by the salt-leaching method, with different initial concentrations $(8,10,12$ and $16 \%$, in wt.\%), followed by freeze-drying. The structural conformation of silk fibroin was confirmed by Fourier transform infra-red spectroscopy (FTIR) and X-ray diffraction (XRD). The morphology and microstructure of the scaffolds were assessed by scanning electron microscopy (SEM) and microcomputed tomography (micro-CT). The static and dynamic mechanical properties were characterized by both compressive tests and dynamic mechanical analysis (DMA). The water uptake and degradation ratios were registered for different time periods, ranging from $3 \mathrm{~h}$ to 30 days. Finally, the morphology and mechanical properties of the scaffolds were also analyzed, by SEM and DMA, respectively.

\section{Materials and methods}

\subsection{Materials}

Cocoons of Bombyx mori were supplied by the Portuguese Association of Parents and Friends of Mentally Disabled Citizens (APPACDM, Portugal). In this study, commercial grade granular sodium chloride (Portugal) was used. Silicon tubing was purchased from Deltalab (Spain). The remaining materials and reagents were obtained from Sigma-Aldrich, unless otherwise indicated.

\subsection{Preparation of concentrated silk fibroin aqueous solution}

Bombyx mori silk fibroin was prepared as reported elsewhere with minor modifications [16]. In brief, cocoons were boiled for $1 \mathrm{~h}$ in an aqueous sodium carbonate solution $(0.02 \mathrm{M})$ and then rinsed thoroughly with distilled water in order to extract the glue-like protein sericine and wax. The purified silk fibroin was dissolved in $9.3 \mathrm{M}$ lithium bromide solution at $70{ }^{\circ} \mathrm{C}$ for $1 \mathrm{~h}$, yielding a $16 \%(\mathrm{w} / \mathrm{v})$ solution. The solution was dialyzed in distilled water using a benzoylated dialysis tubing (molecular weight cutoff: 2000) for $48 \mathrm{~h}$. Next, the silk fibroin aqueous solution was dialyzed against a $20 \mathrm{wt} . \%$ poly(ethylene glycol) solution

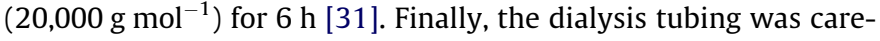
fully washed in distilled water and the silk fibroin solution was collected in a flask. The final concentration of the concentrated silk fibroin was about $20 \mathrm{wt} . \%$, as determined by measuring the dry weight of the silk fibroin solutions. The prepared silk fibroin solution was stored at $4{ }^{\circ} \mathrm{C}$ until further use.

\subsection{Preparation of salt-leached silk fibroin scaffolds}

Granular sodium chloride was prepared by sieving the sodium chloride in an analytical sieve shaker (Retsch) in the range 500$1000 \mu \mathrm{m}$. The prepared concentrated silk fibroin solution was diluted to $8,10,12$ and $16 \mathrm{wt} . \%$, respectively. The scaffolds were prepared by transferring $1 \mathrm{ml}$ of silk fibroin solution (8-16\%) into a silicon tubing ( $9 \mathrm{~mm}$ inner diameter), followed by the addition of $2 \mathrm{~g}$ of granular sodium chloride $(500-1000 \mu \mathrm{m})$ [14]. In the case of the preparation of scaffolds from the 12 and $16 \%$ silk fibroin solutions, the sodium chloride particles were slowly added to the silicon tubing, which was gently tapped to facilitate the precipitation of the salt particles. Following this, the silicon tubing was placed in a Petri dish and dried at room temperature for $48 \mathrm{~h}$. In order to extract the sodium chloride, the tubing was immersed in distilled water for 3 days. Finally, the scaffolds were obtained by using a stainless steel punch (inner diameter: $6 \mathrm{~mm}$ ) in order to remove the outer skin that is generated, followed by freezing at $-80{ }^{\circ} \mathrm{C}$ for 1 day and freeze-drying (Telstar-Cryodos-80, Spain). The prepared silk fibroin scaffolds are designated here as silk-8, silk-10, silk-12 and silk-16, according to the initial concentration (in wt.\%) of the aqueous silk fibroin solution used to prepare the scaffold (Fig. S1).

\subsection{Physicochemical characterization}

\subsubsection{X-ray diffraction}

An X-ray diffractometer (Philips PW 1710, The Netherlands) employing $\mathrm{Cu} K_{\alpha}$ radiation $(\lambda=0.154056 \mathrm{~nm}$ ) was used to analyze the crystallinity of the silk scaffolds on powder. Data were collected for $2 \theta$ values of $0-60^{\circ}$, with a step width of $0.02^{\circ}$ and a counting time of $2 \mathrm{~s}$ per step. The test was repeated three times for each condition.

\subsubsection{Fourier transform infra-red spectroscopy}

The infrared spectra of the silk fibroin powders were recorded on a FTIR spectroscopy (Perkin-Elmer 1600 series equipment, USA). Prior to the analysis, the silk fibroin powders were mixed with potassium bromide in a ratio of $1: 100$ (by wt.), followed by uniaxially pressing into a disk. All spectra were obtained between 4000 and $400 \mathrm{~cm}^{-1}$ at a $4 \mathrm{~cm}^{-1}$ resolution with 32 scans. Each condition was examined for at least three times.

\subsubsection{Scanning electron microscopy}

The cross-sectional morphology of the prepared scaffolds was observed under the scanning electron microscope (Leica Cambridge S-360, UK). Prior to the analysis, specimens were coated with gold using a Fisons Instruments Coater (Polaron SC 502, UK). The cross-sectional morphology of scaffolds after 30 days of degradation was also observed under the scanning electron microscope (NanoSEM-FEI Nova 200). The specimens were coated with $\mathrm{Au} / \mathrm{Pd}$ SC502-314B using a high-vacuum evaporator coater (E 6700, Quorum/Polaron). Three samples were tested for each condition.

\subsubsection{Micro-computed tomography}

The architecture of the silk scaffolds was evaluated using a high-resolution micro-CT Skyscan 1072 scanner (Skyscan, Kontich, Belgium) with a pixel size of $\sim 8 \mu \mathrm{m}$ and an integration time of $1.3 \mathrm{~s}$. The X-ray source was set at $40 \mathrm{keV}$ and $248 \mu \mathrm{A}$. Approximately 300 projections were acquired over a rotation range of $180^{\circ}$, with a rotation step of $0.45^{\circ}$. Data sets were reconstructed using standardized cone-beam reconstruction software (NRecon v1.4.3, SkyScan). The output format for each sample was 300 serial $1024 \times 1024$ bitmap images. Representative data set of the slices was segmented into binary images with a dynamic threshold of 
40-255 (grey values). Then, the binary images were used for morphometric analysis (CT Analyser, v1.5.1.5, SkyScan) and to build the three-dimensional models (ANT 3D creator, v2.4, SkyScan). Three samples were tested for each condition.

\subsubsection{Compression tests}

Compressive tests (dry state) were performed by using a Universal Testing Machine (Instron 4505) with a $1 \mathrm{kN}$ load cell at room temperature. The size of the tested specimens was measured with a micrometer. The lengths of the tested specimens for silk-8, silk-10, silk-12 and silk- 16 were $5.593 \pm 0.242,5.593 \pm 0.330,5.935 \pm 0.257$ and $5.503 \pm 0.187 \mathrm{~mm}$, respectively. The diameters of the tested specimens for silk-8, silk-10, silk-12 and silk-16 were $5.355 \pm$ $0.182,5.534 \pm 0.154,5.435 \pm 0.093$ and $5.203 \pm 0.062 \mathrm{~mm}$, respectively. The cross-head speed was set at $2 \mathrm{~mm} \mathrm{~min}^{-1}$ and tests were run until a $60 \%$ reduction in specimen height had been achieved. The elastic modulus $(E)$ was defined by the slope of the initial linear section of the stress-strain curve. A minimum number of seven specimens were tested, with $E$ being the average of all the measurements.

\subsubsection{Dynamic mechanical analysis}

The viscoelastic measurements were performed using a TRITEC8000B dynamic mechanical analyzer (Triton Technology, UK) in the compressive mode. The measurements were carried out at $37^{\circ} \mathrm{C}$. Samples were cut into cylindrical shapes of approximate $6 \mathrm{~mm}$ diameter and $5 \mathrm{~mm}$ thickness (measured each sample accurately with a micrometer). The scaffolds were always analyzed whilst immersed in a liquid bath placed in a Teflon ${ }^{\circledR}$ reservoir. The scaffolds had previously been immersed in a phosphate-buffered saline solution (PBS) until equilibrium was reached $\left(37^{\circ} \mathrm{C}\right.$ overnight). The geometry of the samples was then measured and the samples were clamped in the DMA apparatus and immersed in PBS solution. After equilibration at $37^{\circ} \mathrm{C}$, the DMA spectra were obtained during a frequency scan between 0.1 and $10 \mathrm{~Hz}$. The experiments were performed under a constant strain amplitude $(50 \mu \mathrm{m})$. A small preload was applied to each sample to ensure that the entire scaffold surface was in contact with the compression plates before testing, and the distance between plates was equal for all scaffolds being tested. A minimum of three samples were used for each condition.

\subsubsection{Water uptake and weight-loss-related tests}

The water uptake and degradation behaviour of the silk fibroin scaffolds were assessed after immersion in an isotonic saline solution (ISS; $0.154 \mathrm{M}$ sodium chloride aqueous solution, $\mathrm{pH} 7.4$ ) for time periods ranging from $3 \mathrm{~h}$ to 30 days [36]. All experiments were conducted at $37^{\circ} \mathrm{C}$ and dynamic condition $(60 \mathrm{rpm})$ in a water bath (GFL 1086). After each time point, the specimens were removed from the ISS and the weights were determined immediately after adsorption of the excess of surface water using a filter paper. The water uptake was calculated using the following expression:

water uptake $=\left[\left(m_{\mathrm{w}, t}-m_{0}\right) / m_{0}\right] \times 100 \%$

where $m_{0}$ is the initial weight of the specimen before hydration, and $m_{\mathrm{w}, t}$ is the wet weight of the specimens at time $t$ after being removed from the ISS.

After determination of the water uptake, the specimens were washed with distilled water and dried in an oven at $60{ }^{\circ} \mathrm{C}$ for $24 \mathrm{~h}$. The weight loss was determined using the following Q2 expression:

weight $\operatorname{loss}(\%)=\left[\left(m_{0}-m_{\mathrm{d}, t}\right) / m_{0}\right] \times 100 \%$

where $m_{\mathrm{d}, t}$ is the dry weight of the specimen degraded for a certain period of time, after drying at $60^{\circ} \mathrm{C}$ until a constant weight was reached. Six specimens were used for each condition.
The surface morphology and dynamic mechanical properties of the specimens were analyzed as aforementioned, after 30 days of soaking. Three specimens were tested for each condition.

\subsection{Statistical analysis}

The mean pore size, mean pore size distribution, mean trabecular thickness, mean trabecular thickness distribution, mean porosity, mean interconnectivity, mechanical results, water uptake ratio and degradation ratio were presented as means \pm standard deviation. First, a one-way analysis of variance was used to evaluate the data, then comparisons between two means were analyzed using Tukey's test, with statistical significance set at $p<0.05$. At least three specimens were used in each condition.

\section{Results and discussion}

\subsection{Chemical structure}

Several conformations (random coil, silk-I, silk-II and $310^{- \text {helix) }}$ of silk fibroin have been identified previously by means of XRD, infra-red spectroscopy and ${ }^{13} \mathrm{C}$ nuclear magnetic resonance (NMR) [37-42]. Random coil is an amorphous structure presented in aqueous silk fibroin solution of low concentration, in lyophilized silk fibroin, and also in silk fibroin films cast under controlled conditions $[31,43,44]$. Silk-I is a metastable form which can be produced by drying the silk gland contents or by controlling the

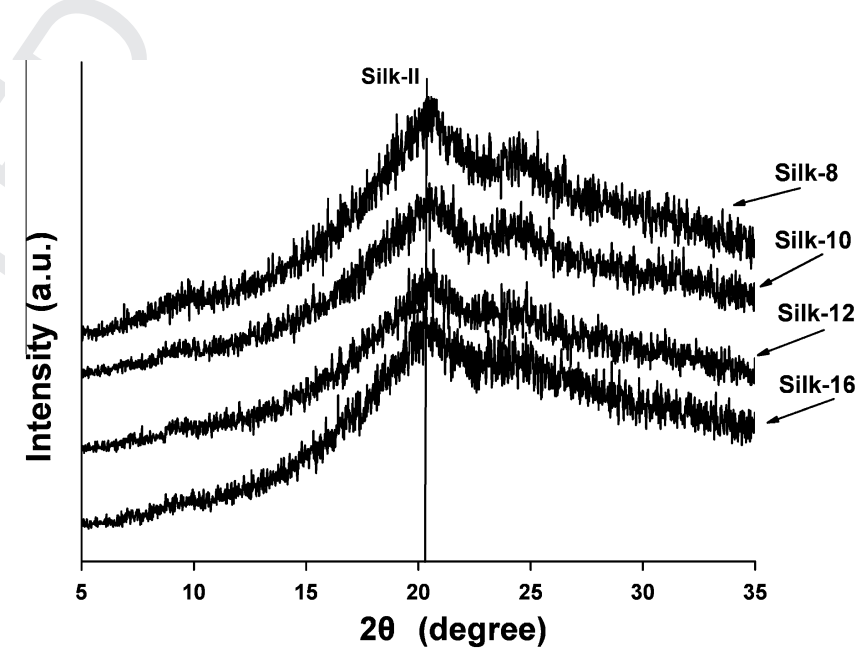

Fig. 1. XRD patterns of the silk fibroin scaffolds obtained by combining the saltleaching and freeze-drying methodologies.

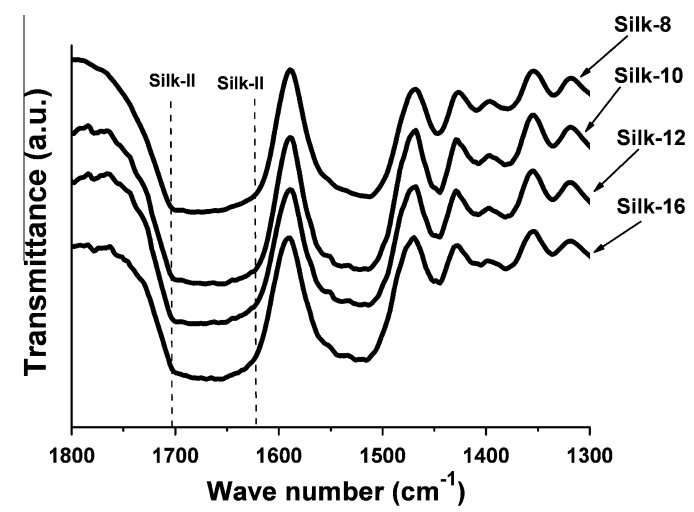

Fig. 2. FTIR spectra of the silk fibroin scaffolds obtained by combining the saltleaching and freeze-drying methodologies. 

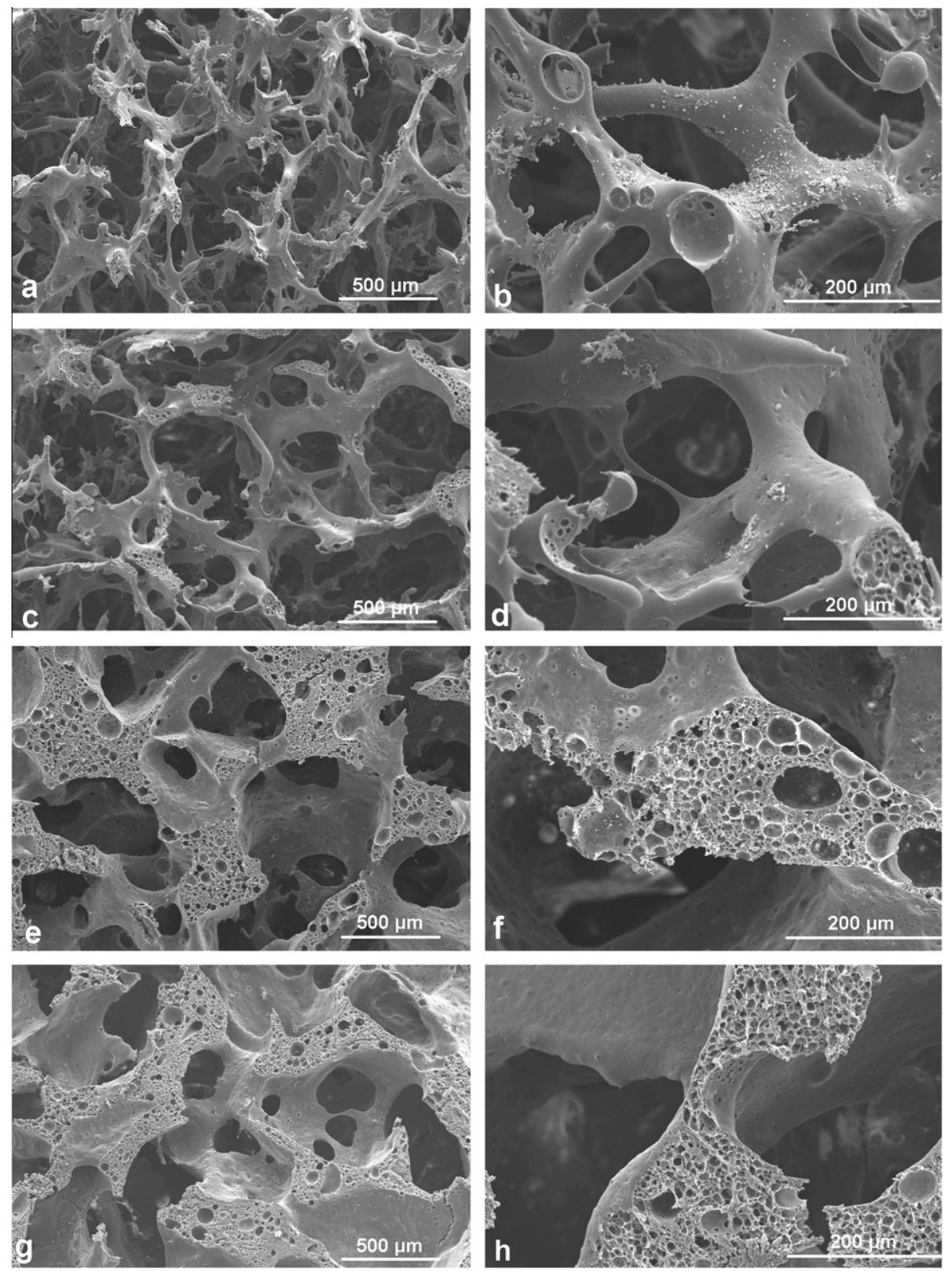

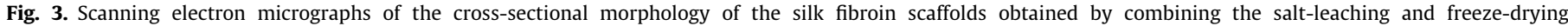
methodologies. (a, b) Silk-8; (c, d) silk-10; (e, f) silk-12; (g, h) silk-16.

water annealing of silk fibroin films at room temperature [42-44]. Silk-II is an antiparallel $\beta$-pleated sheet structure which exists in natural silk fibroin fibers or can be produced from aqueous silk fibroin solutions treated with physical shear or organic solvents $[31,38]$. The $33_{10}$-helix structure can be produced by casting silk fibroin solution in a fluoro-based solvent system [41,42].

Jin and Kaplan [31] listed the fingerprint reflection of XRD for silk-I and silk-II (in angstroms): 9.8 (II), 7.4 (I), 5.6 (I), 4.8 (II), 4.4 (I), 4.3 (II), 4.1 (I), 3.6 (I), 3.2 (I), 2.8 (I). Kim et al. [14] defined the crystal structure of silk fibroin in the aqueous-derived salt-leached scaffold as silk-II, as evidenced by XRD peaks at $2 \theta$ of $8.5^{\circ}(10.37 \AA$ ), $20.8^{\circ}\left(4.35 \AA\right.$ ) and $24.6^{\circ}$ (3.62 Å). Other studies [43,44] have described the preparation of water-insoluble silk fibroin, mainly of the silk-I structure. These studies reported that XRD peaks $(2 \theta)$ at $24.2^{\circ}\left(3.7 \AA\right.$ ) and at around $22.2^{\circ}$ and $25^{\circ}$ were assigned to the silk-I structure. Moreover, these studies showed that both silk-I and silk-II structures coexisted in a methanol-annealed silk fibroin film. Tamada [45] reported that $2 \theta=24-25^{\circ}$ was attributed to the silk-I structure and both the silk-I and silk-II conformations presented in the same scaffold. These observations are supported by another interesting study [37], which reported the production of silk fibroin with variable amounts of silk-I and silk-II.

In this study, XRD analysis was performed to determine the crystalline structure in the scaffolds (Fig. 1). From Fig. 1, it is possible to observe that there were no significant differences between the four groups in respect to the peak positions. The peaks at 20.5$20.8^{\circ}$ can be assigned to silk-II based on the previous studies in the literature $[14,31,37,43,44]$. All these peaks are broad and of low intensity, which is an indication that the prepared scaffolds possess low crystallinity and an uncertain amount of random coil.

FTIR is also a reliable technique to further confirm the crystal conformation in silk fibroin [37,43-45]. Fig. 2 shows the FTIR spectra of silk fibroin scaffolds obtained by combining sat-leaching and freeze-drying methodologies. The peaks located at 1701-

Please cite this article in press as: Yan L-P et al. Macro/microporous silk fibroin scaffolds with potential for articular cartilage and meniscus tissue engineering applications. Acta Biomater (2011), doi:10.1016/j.actbio.2011.09.037 

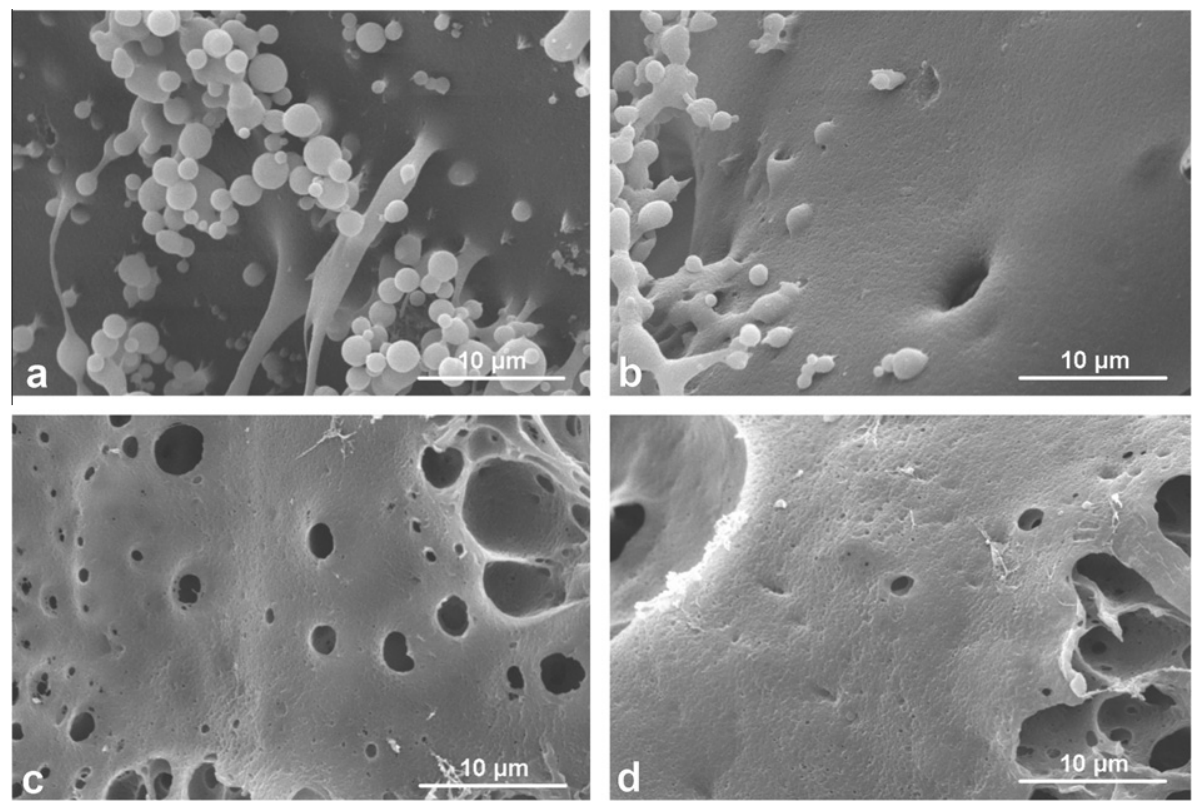

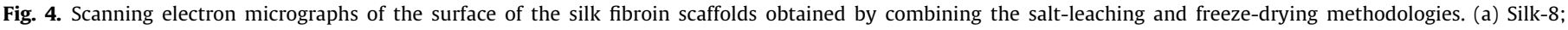
(b) silk-10; (c) silk-12; (d) silk-16.

$1704 \mathrm{~cm}^{-1}$ and $1622-1627 \mathrm{~cm}^{-1}$ can be attributed to the silk-II structure $[43,44,46]$. The corresponding peak positions of the main groups are mostly the same for all scaffolds. It should be noted that the way the FTIR was performed can also affect the final spectra, as reported by Demura et al. [47].

By correlating the XRD and FTIR results, it is possible to state that the prepared silk fibroin scaffolds possess a silk-II structure. This observation is consistent with those reported in previous studies using the salt-leaching methodology [14,28]. In this study, it was not possible to determine the content of the structure conformation in the different scaffolds. Further quantitative ${ }^{13} \mathrm{C}$ NMR analysis $[28,37]$ and studies on conformational changes in a realtime manner need to be addressed.

\subsection{Morphology and microstructure}

Salt leaching is a versatile method that has attracted a great deal of attention with regard to tissue-engineered scaffolding $[14,19,28]$. In this study, the pores morphology of the prepared silk fibroin scaffolds was investigated using SEM. From the obtained images, mainly two types of pore size were observed among the cross-section of the scaffolds (Fig. 3). The morphology of the developed scaffolds varied among the different initial concentrations used. Silk-8 and silk-10 both presented a branched-like morphology (Fig. 3a and c), while silk-12 and silk-16 seemed to possess thicker trabecular structures, based on SEM observation (Fig. 3e and g). From Fig. 3, pores of several hundred micrometers were observed (named L-pores; Fig. 3a, c, e and g). There were also pores less than $100 \mu \mathrm{m}$ in size (named S-pores) distributed inside the trabeculae of the L-pores (Fig. 3b, d, f and h).

Fig. 4 shows the SEM images of the surface of silk fibroin scaffolds obtained by combining the salt-leaching and freeze-drying methodologies. From Fig. 4, it can be seen that the surfaces of the different scaffolds are distinct. An interesting finding was the presence of silk fibroin microspheres on the surface of silk-8 and silk-10, of sizes ranging from several hundred nanometers to several micrometers (Fig. 4a and b). Additionally, pores less than $10 \mu \mathrm{m}$ in size were observed on the surface of silk-12 and silk-16 (Fig. 4c and d).
In previous studies $[14,28]$, uniform pore size distribution was achieved since the salt particles used were all within a narrow size range. The pore sizes of the scaffolds produced in the present study are not as homogeneous as those one found in the literature, since $\mathrm{NaCl}$ particles across a wide size range were used in this study. The L-pores are formed by the extraction of the salt particles and, since the salt particles partially dissolve during the precipitation, the Lpores are not the same size as the original $\mathrm{NaCl}$ particles $[14,28]$. The sizes of the L-pores in this work are adequate for bone tissue engineering, as proposed elsewhere $[2,48]$. The finding of S-pores in the trabeculae of L-pores is consistent with the observations reported by Makaya et al. [28], though presenting different morphology.

As can be seen in Fig. S2, there are also microporous structures in the trabeculae of all the air-dried scaffolds that were produced by the salt-leaching methodology. In this case, the porosity is explained as being the result of some recrystallization of the dissolved salt in the system inside the silk structure. When compared with the S-pores within the scaffolds produced by the combination of the salt-leaching and freeze-drying methodologies, the latter seem to possess high porosity in the trabeculae. Thus, it is clear that the microporosity presented by the scaffolds produced by combining salt leaching and freeze-drying may result from the combined effect of the recrystallization of the dissolved salt particles in the system and the lyophilization process. This unique macro/microporous structure is of great interest for tissue engineering. The size of the macropores (L-pores) is adequate for the transmission of nutrients and metabolic products, for cell ingrowth and for the growth of new vessels $[2,48]$. The micropores (S-pores) could help to tailor the degradation of the scaffolds, increase the cell seeding efficiency and enhance the cells' adhesion in future applications.

Regarding the formation of the silk fibroin microspheres, our observations are in agreement with previous findings [14,31]. During the precipitation of the silk fibroin, residue silk fibroin in aqueous solution tends to form micelles, which will subsequently selfassemble into microspheres with increasing ion concentration. In the case of highly concentrated silk fibroin solutions, such as silk-12 and silk-16, the gelation of the silk fibroin was dominant 

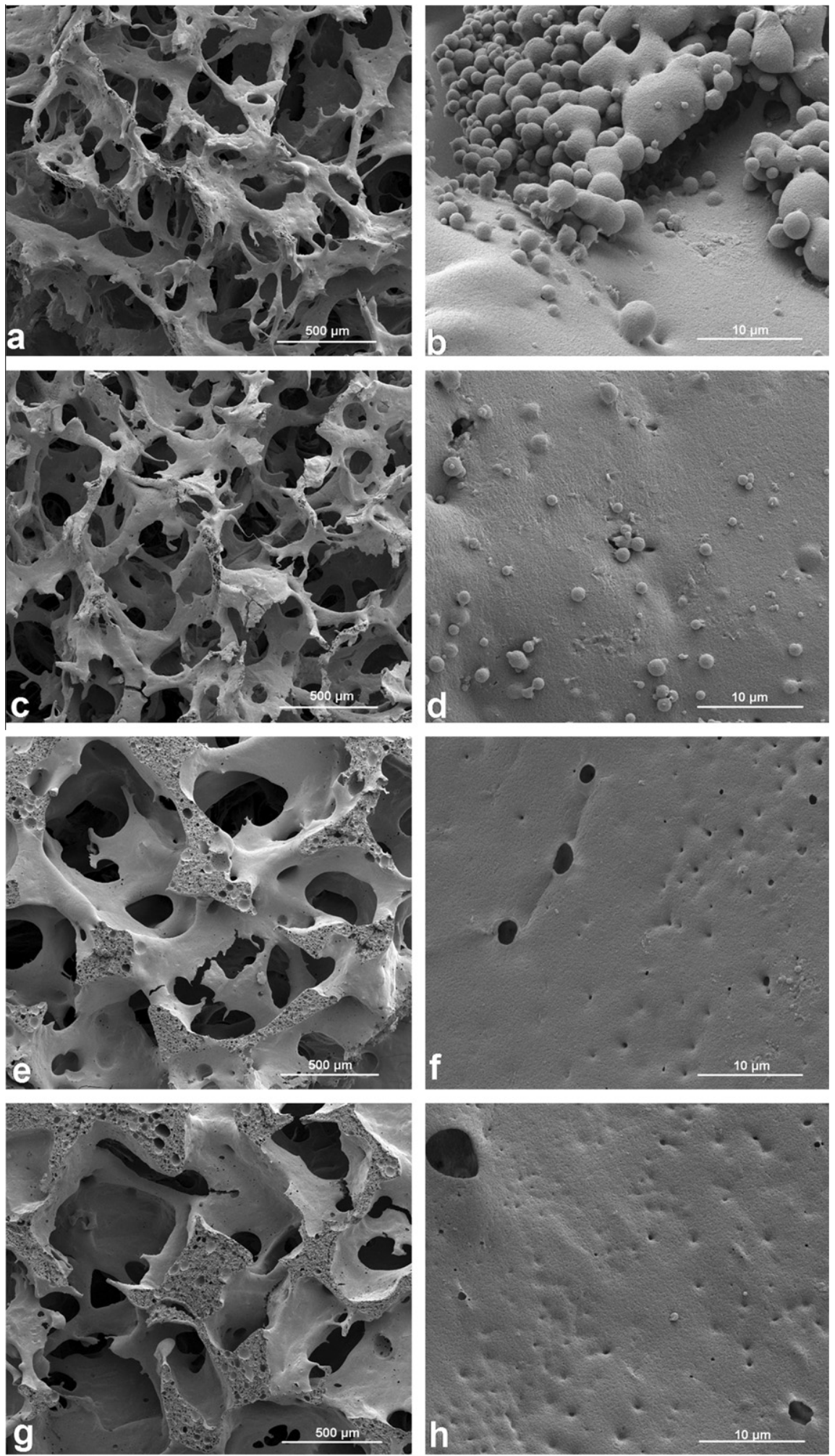

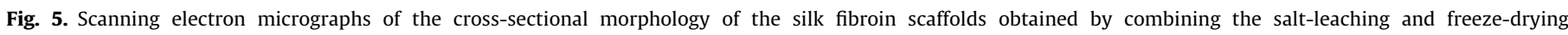

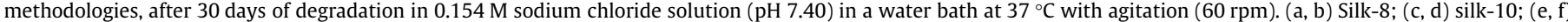
silk-12; (g, f) silk-16.

without the formation of self-assembled microspheres at the surface.

The microstructure and architecture of the scaffolds are crucial parameters for tissue engineering applications since they can affect the final outcome of the tissue regeneration. Compared to conven- tional methods in determination of the pore size and porosity of the scaffold, such as liquid displacement, mercury and flow porosimetry, gas pycnometry, gas adsorption and SEM (combine with computer software), micro-CT emerges as a promising alternative $[49,50]$. It is not only non-destructive, fast and accurate, but also

Please cite this article in press as: Yan L-P et al. Macro/microporous silk fibroin scaffolds with potential for articular cartilage and meniscus tissue engineering applications. Acta Biomater (2011), doi:10.1016/j.actbio.2011.09.037 


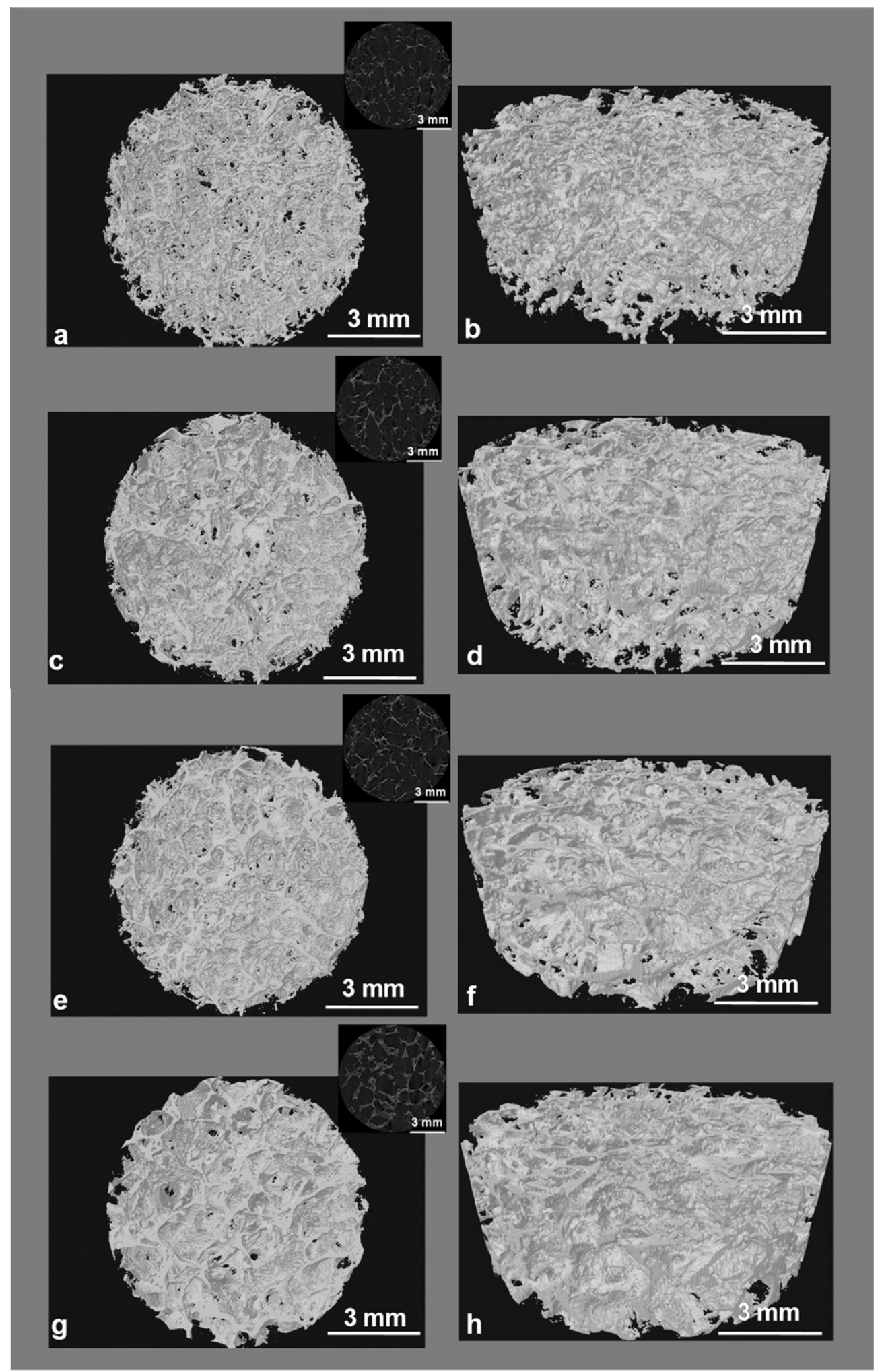

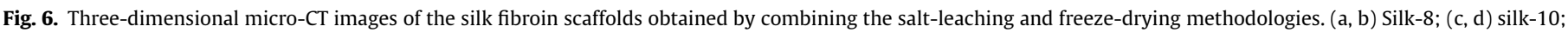
(e, f) silk-12; (g, f) silk-16. The inset images are two-dimensional images of the scaffolds.

provides a comprehensive overview of the microstructure of the scaffolds. In this study, micro-CT was employed to investigate the architecture of the scaffolds (Fig. 6). From the three- and two-dimensional images (Fig. 6, inset), it was observed that the scaffolds were highly porous and presented interconnected pores, and the thickness of the pore walls for the larger pores (L-pores) seemed to increase with increasing silk fibroin concentration. These results were consistent with the SEM observations.

Micro-CT morphometric analysis of the silk fibroin scaffolds obtained by combining the salt-leaching and freeze-drying methodologies can be seen in Figs. 7-10. The mean pore size of the scaffolds was between 200 and $300 \mu \mathrm{m}$ (Fig. 7a). No statistically

Please cite this article in press as: Yan L-P et al. Macro/microporous silk fibroin scaffolds with potential for articular cartilage and meniscus tissue engineering applications. Acta Biomater (2011), doi:10.1016/j.actbio.2011.09.037 

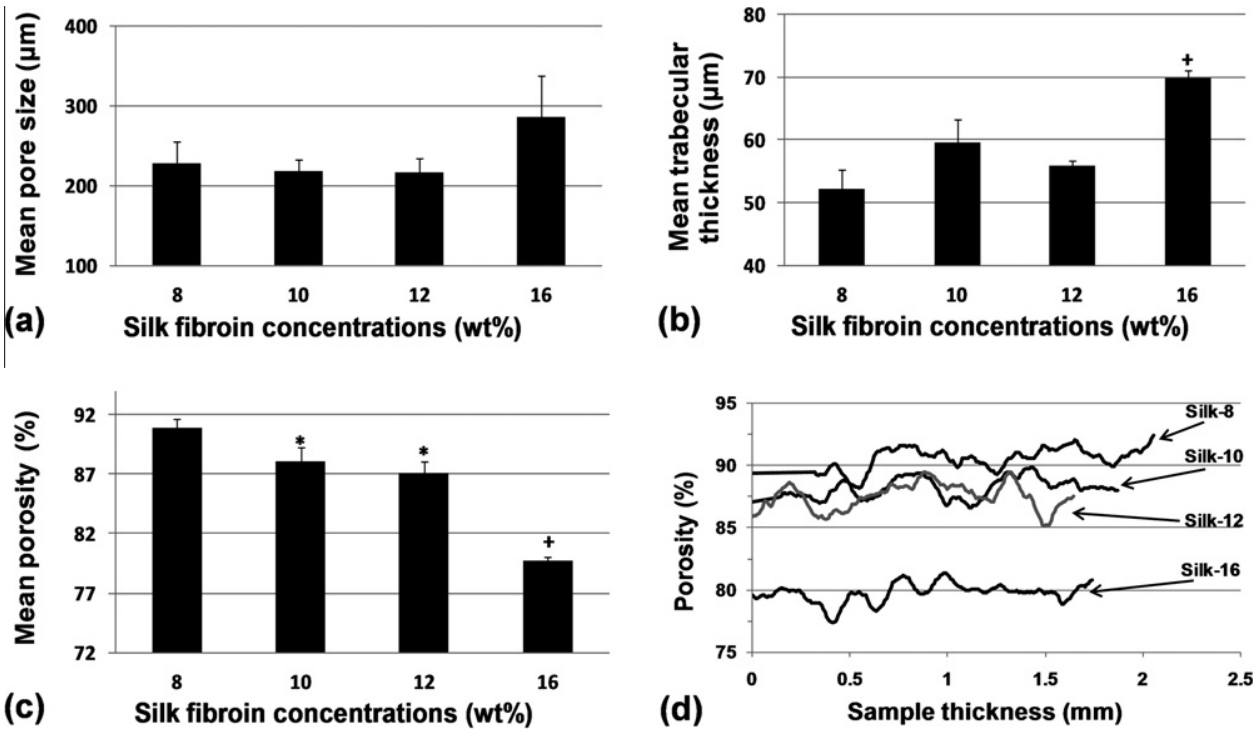

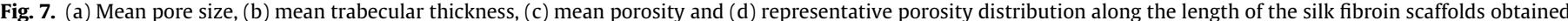

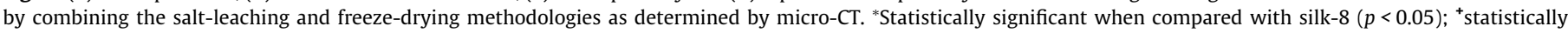
significant when compared with silk-8, silk-10 and silk-12 $(p<0.05)$.
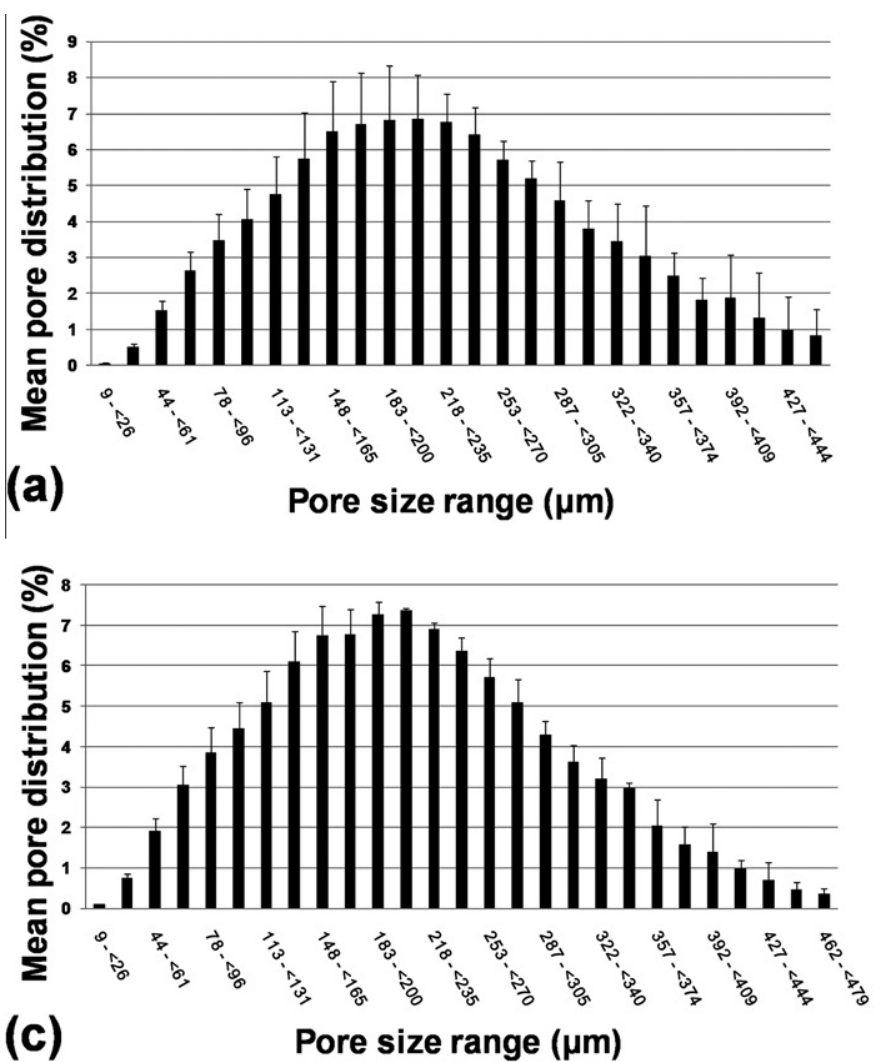
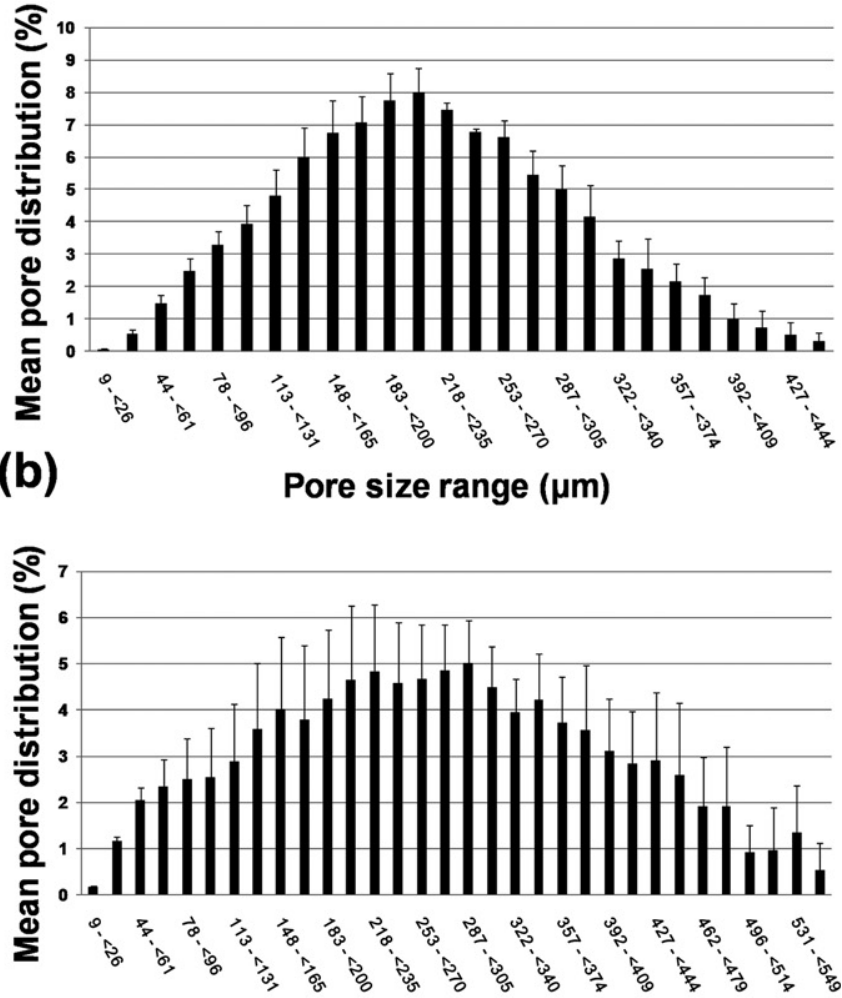

(d)

Pore size range $(\mu \mathrm{m})$

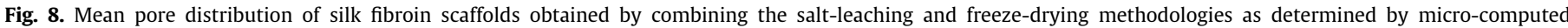
tomography. (a) Silk-8; (b) silk-10; (c) silk-12; (d) silk-16.

significant differences for pore size were found among the scaffolds, though silk-16 presented the highest mean pore size. Silk16 also presented a wider pore distribution than the other scaffolds (Fig. 8). A higher mean trabecular thickness (Fig. 7b) and a wider trabecular distribution (Fig. 9) in silk-16 were also observed. As can be seen in Fig. 7c, the porosity decreased from $90.8 \pm 0.9$ to
$79.8 \pm 0.3 \%$ when the silk fibroin concentration was increased from 8 to $16 \%$. The porosity is homogeneously distributed (Fig. 7d) in the core of all the developed scaffolds. In this study, the interconnectivity of the prepared scaffolds was also evaluated (Fig. 10). The interconnectivity values of the prepared scaffolds were between $92.3 \pm 1.3$ and $97.4 \pm 0.5 \%$. As the silk fibroin concentration in-

Please cite this article in press as: Yan L-P et al. Macro/microporous silk fibroin scaffolds with potential for articular cartilage and meniscus tissue engineering applications. Acta Biomater (2011), doi:10.1016/j.actbio.2011.09.037 

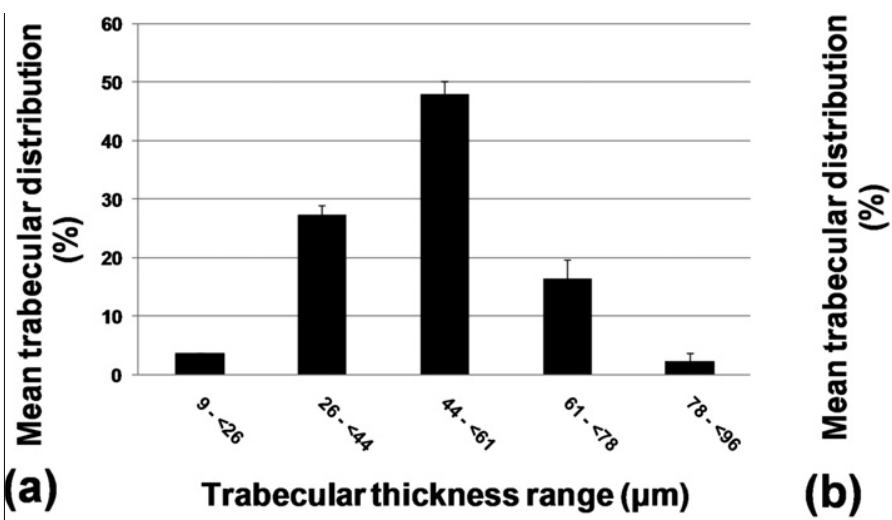

(b)

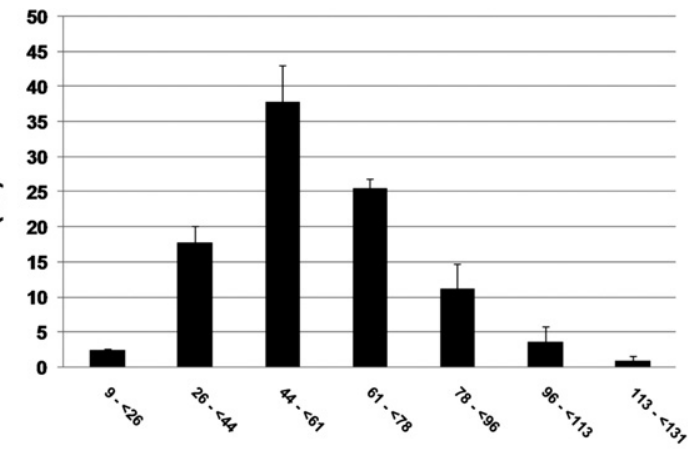

Trabecular thickness range $(\mu \mathrm{m})$

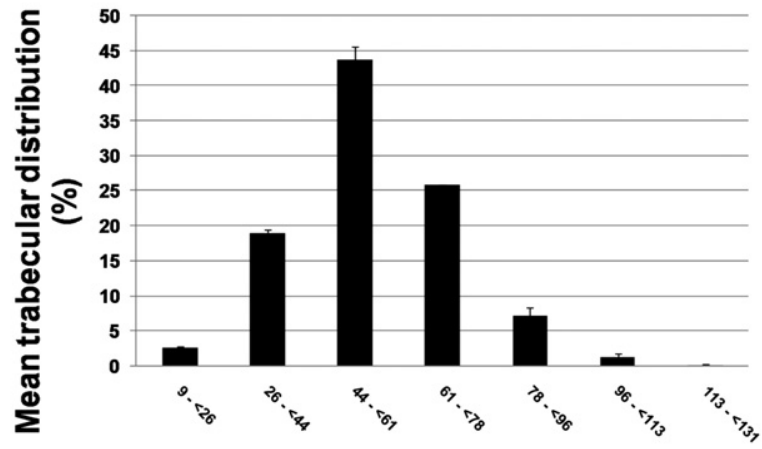

(c)

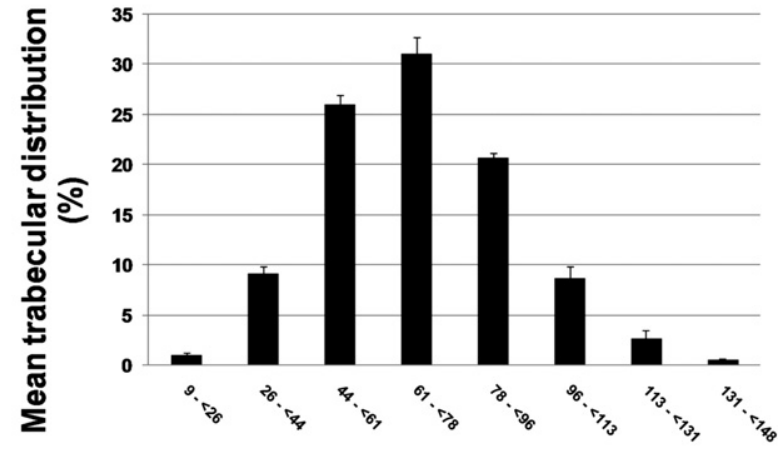

(d)

Trabecular thickness range $(\mu \mathrm{m})$

Fig. 9. Mean trabecular distribution of silk fibroin scaffolds obtained by combining the salt-leaching and freeze-drying methodologies as determined by micro-CT. (a) Silk-8; (b) silk-10; (c) silk-12; (d) silk-16.

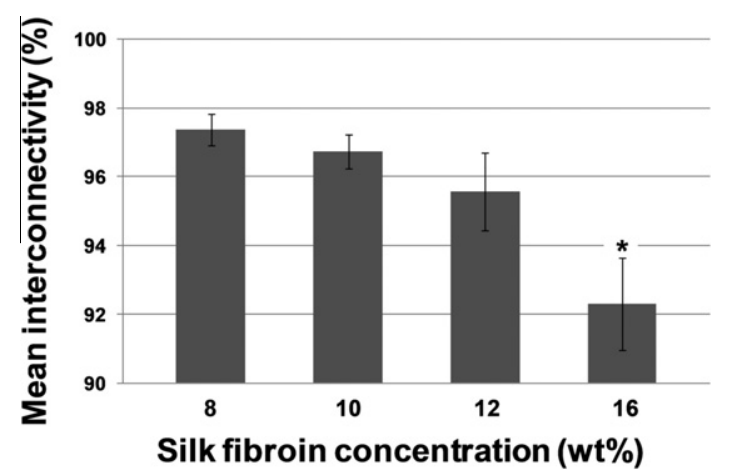

Fig. 10. Mean interconnectivity of the silk fibroin scaffolds obtained by combining the salt-leaching and freeze-drying methodologies, as determined by microcomputed tomography. *Statistically significant when compared with silk-8, silk10 and silk-12 $(p<0.05)$. creased, the mean interconnectivity tended to decrease. Even though the lowest interconnectivity was observed in silk-16, it was still as high as $92.3 \pm 1.3 \%$.

The microstructure results were related to the initial silk fibroin concentrations. During the precipitation, the amount of silk fibroin precipitated increased by means of increasing the concentration of the silk solution. The higher the concentration of silk fibroin solutions used, the lower the porosity and higher trabecular thickness can be achieved. Since the salt particles used in each case were in the same range of size, the differences in the mean pore sizes of the scaffolds were not statistically significant. The mean pore size was obtained from measuring the sizes of the L-pores and S-pores. This explains why the value is lower than the size of the L-pore

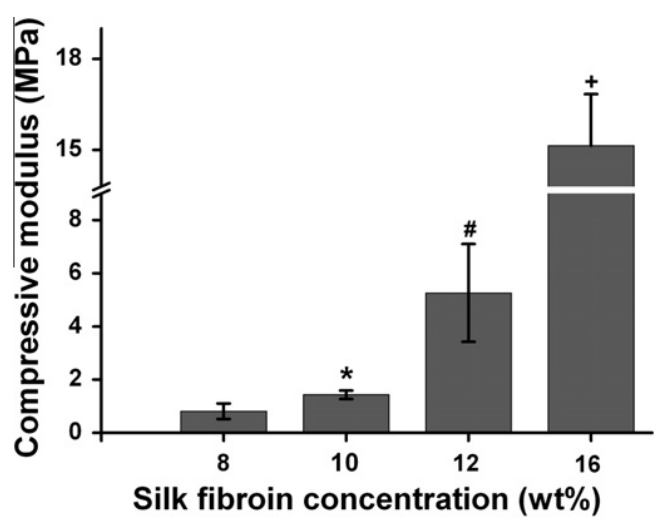

Fig. 11. Compressive modulus of the silk fibroin scaffolds obtained by combining the salt-leaching and freeze-drying methodologies. *Statistically significant when compared with silk-8 $(p<0.05)$; ${ }^{*}$ statistically significant when compared with silk8 and silk-10 $(p<0.05) ;{ }^{+}$statistically significant when compared with silk-8, silk-10 and silk-12 $(p<0.05)$.

observed under SEM. In this study, both the L-pores and the S-pores contributed to the interconnectivity of the scaffolds. From the SEM images (Fig. 3), the L-pores were nearly completely interconnected, while the S-pores inside the trabeculae of the L-pores were not as well interconnected as the L-pores. Silk-16 presented the highest trabecular thickness (Fig. 7b), which could result in the greatest amount of S-pores (Fig. 3b, d, f and h). This explains the lowest interconnectivity of the silk- 16 . Moreover, the homogeneous porosity distribution inside the scaffolds indicated that the wide size range of salt particles did not affect the homogeneity of the scaffolds. 


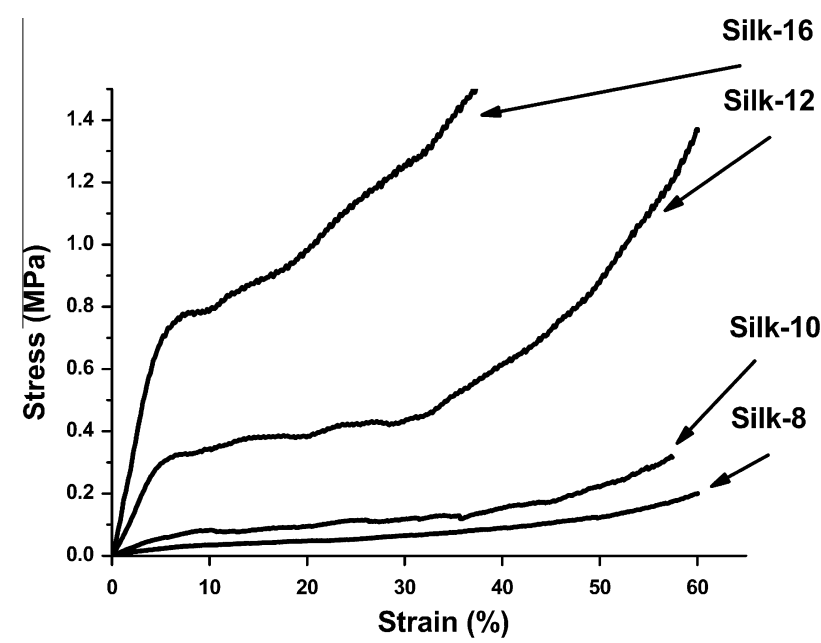

Fig. 12. Stress-strain plot of the silk fibroin scaffolds obtained by combining the salt-leaching and freeze-drying methodologies.

It has been reported that a pore size larger than $300 \mu \mathrm{m}$ is suitable for the formation of new bone and capillaries [48]. In Fig. 8, it was found that silk- 8 , silk10 and silk-12 possessed about $15 \%$ pores of size larger than $300 \mu \mathrm{m}$, while silk-16 presented an even higher ratio. It has also been suggested that a highly interconnected pore network with high porosity would benefit cell growth, the transport of nutrients and metabolic waste, the deposit of cellular matrix and the ingrowth of the newly formed tissue $[2,28]$. In this study, by developing silk fibroin scaffolds that combine high interconnectivity (all above $90 \%$ ), high porosity (all above $79 \%$ ) and a macro/microporous architecture, we firmly expect to obtain promising scaffold candidates for tissue engineering applications.

\subsection{Mechanical properties}

Fig. 11 shows the mechanical properties of silk fibroin scaffolds obtained by combining the salt-leaching and freeze-drying meth-
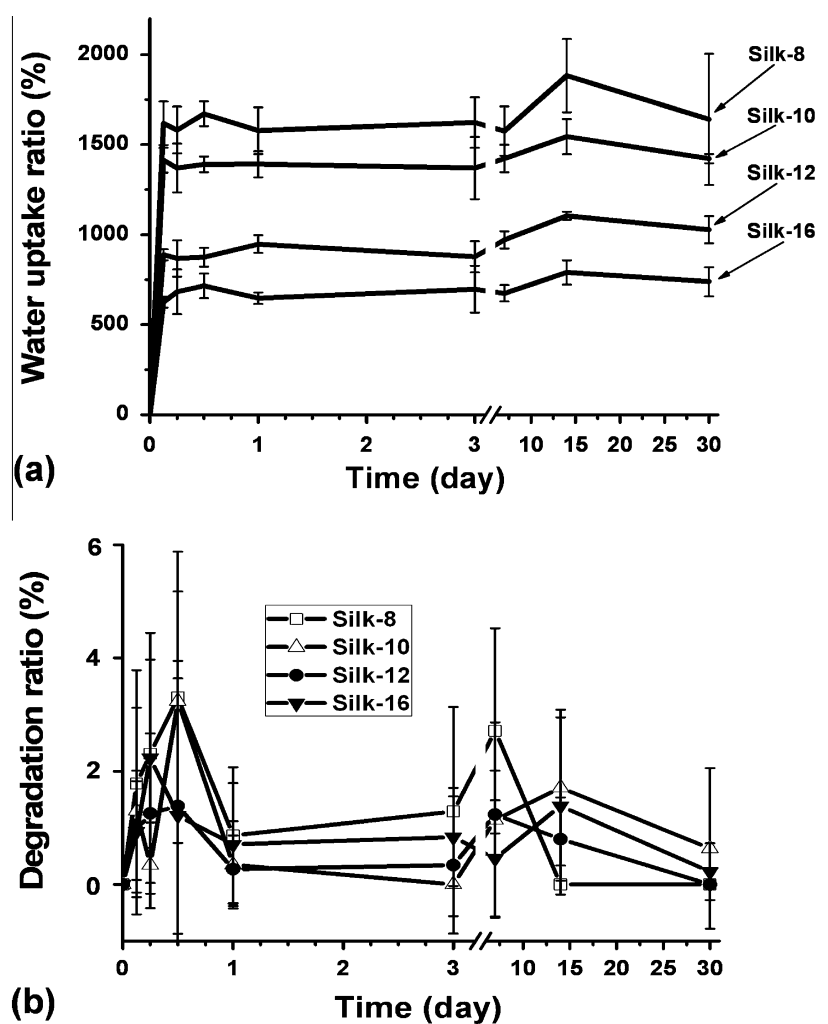

Fig. 14. (a) Water uptake and (b) degradation profile of the silk fibroin scaffolds obtained by combining the salt-leaching and freeze-drying methodologies for times of up to 30 days.

odologies evaluated under compression testing. The static compressive modulus of the dried silk fibroin scaffolds increased dramatically with increasing silk fibroin concentration: it increased from $0.81 \pm 0.29$ to $15.14 \pm 1.70 \mathrm{MPa}$ as the silk fibroin concentration increased from 8 to $16 \%$. The representative
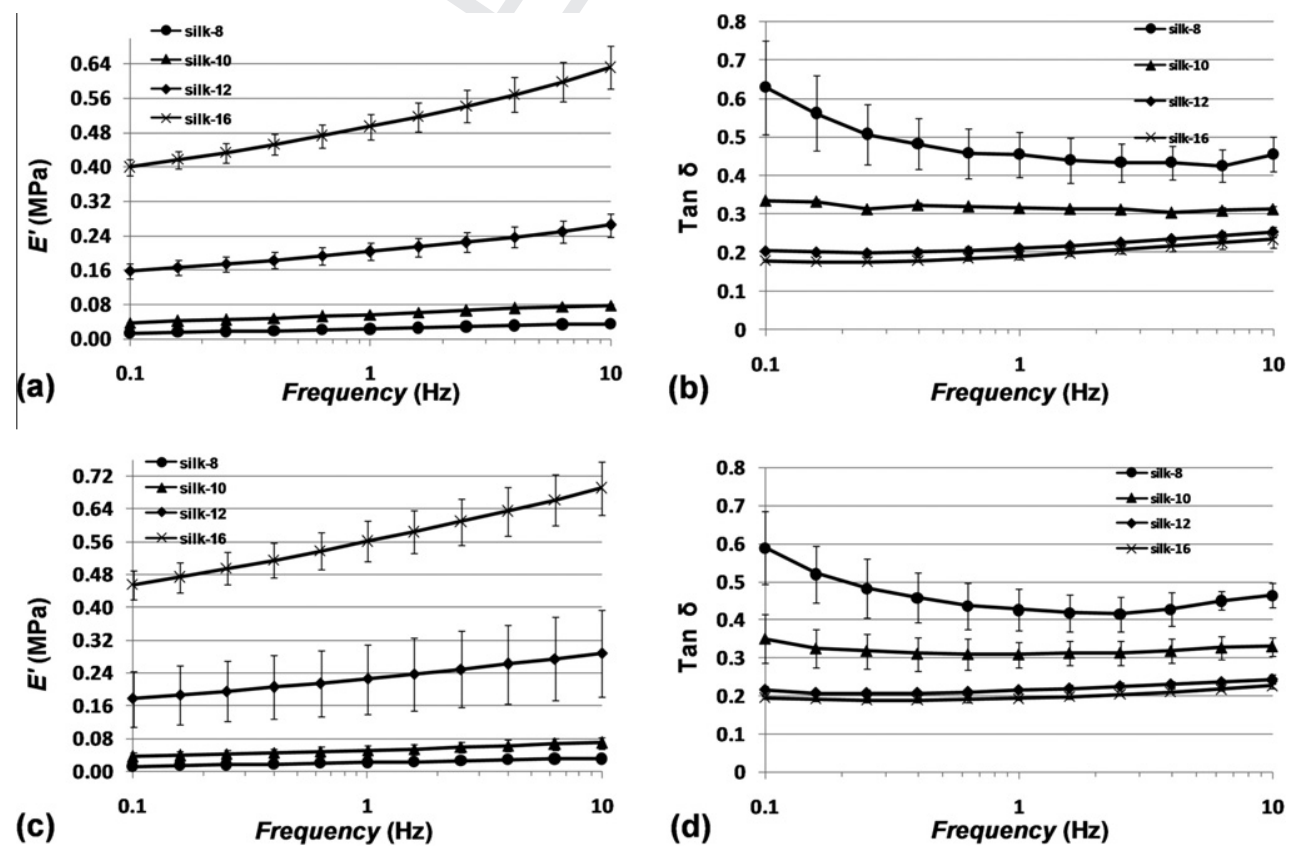

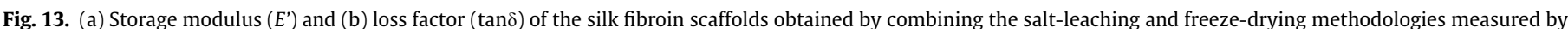

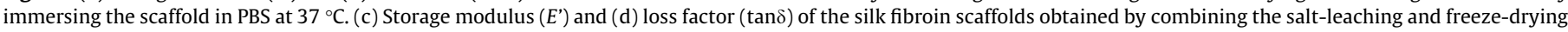
methodologies measured by immersing the scaffold in PBS at $37^{\circ} \mathrm{C}$, after 30 days of soaking.

Please cite this article in press as: Yan L-P et al. Macro/microporous silk fibroin scaffolds with potential for articular cartilage and meniscus tissue engineering applications. Acta Biomater (2011), doi:10.1016/j.actbio.2011.09.037 
stress-strain plot (Fig. 12) shows that the compressive strength of the scaffolds improved remarkably, from 0.05 to $0.79 \mathrm{MPa}$, when the silk fibroin concentration increased from 8 to $16 \%$. Regardless of the different characterization conditions, the compressive moduli of silk- 8 and silk-10 were lower than those of scaffolds with the same concentrations reported in the previous studies [14]. This can be explained by the homogeneous pore size distribution reported by Kim et al. [14]. The compressive modulus of silk-16 was higher compared to other previously reported data for pure silk fibroin scaffolds prepared by the salt-leaching or gas-forming method $[14,19,28]$. Notably, it was higher than that of the scaffolds prepared with $17 \%$ silk fibroin in hexafluoroisopropanol [19].

Since the scaffolds are expected to be used in a hydrated environment, it is of relevance to predict their biomechanical behavior by testing the mechanical properties in realistic conditions, using DMA analysis. Fig. 13 shows the mechanical properties of silk fibroin scaffolds obtained by combining the salt-leaching and freeze-drying methodologies determined by DMA analysis. From the obtained data, we can observe that the storage modulus of all the groups increased with increasing frequency from 0.1 to $10 \mathrm{~Hz}$, although the increase profiles were different (Fig. 13a). The modulus values of silk- 8 and silk-10 increase at lower rates compared to silk-12 and silk-16. For the tested frequencies, the moduli incresed from $12.8 \pm 4.2$ to $33.7 \pm 7.5 \mathrm{kPa}, 37.6 \pm 1.7$ to $77.9 \pm 4.4 \mathrm{kPa}, 158.0 \pm 16.8$ to $264.1 \pm 26.8 \mathrm{kPa}$ and $399.2 \pm 19.6$ to $630.3 \pm 49.8 \mathrm{kPa}$ for silk-8, silk-10, silk-12 and silk-16, respectively. These results proved that the stiffness of the scaffolds improved with increasing silk fibroin concentration.

Additionally, at each testing frequency, the modulus of the scaffolds exhibited concentration dependence, and its trend was the same as that observed in the static and dry status compressive test (Fig. 11). The distinct mechanical properties of the developed scaffolds can be explained by the differences in porosity and microstructure for each group. On the other hand, previous studies have shown that the value of the equilibrium compressive modulus of silk fibroin scaffolds (prepared from $17 \%$ silk fibroin in hexafluoroisopropanol) is less than $10 \mathrm{kPa}$ - which is lower than the values obtained for human meniscus (23.6-47.8 kPa) and articular cartilage (0.4-0.8 MPa) [32,51-53]. Although the analysis in this study was not performed under equilibrium conditions, the values of compressive modulus obtained for silk-12 and silk-16 are comparable with those found in the literature $[14,19]$. Based on the higher compressive modulus values of silk-12 and silk-16 compared to the literature values [14,19], the equilibrium moduli of silk-12 and silk-16 are expected to be higher than those of the silk fibroin scaffolds prepared in the previous studies, making them suitable to be used in meniscus (silk-10 and silk12) and cartilage (silk-16) tissue engineering. At present, studies are ongoing to evaluate the aggregate and equilibrium moduli of the silk fibroin scaffolds, as well as to test their biological performance.

The loss factor is the ratio of the amount of energy dissipated by viscous mechanisms relative to energy stored in the elastic component. Comparing the loss factor data of the four groups of scaffolds, it is found that the viscosity values decreased as the silk fibroin concentration increased at the tested frequency (Fig. 13b). Concerning the damping property of each group, it is shown that there are not many differences in silk-10, silk-12 and silk-16 at all the tested frequencies, evidencing that these three groups of scaffolds present stable elasticity and viscosity. This property endows the prepared scaffolds with potential to be applied for engineering elastic tissues, such as articular cartilage and meniscus. With higher standard deviations, however, the loss factor of silk-8 seems to decrease with increasing frequency, indicating the weaker stiffness of this group compared with the other groups.

There were distinct differences in mechanical performance between the scaffolds tested in the dry status and in the wet. These differences can be associated to the seven smaller internal hydrophilic blocks and two large hydrophilic blocks at the chain ends among the silk fibroin heavy chain [14]. In the wet status, the hydrophilic groups in silk fibroin are hydrated and consequently the stiffness of the scaffolds decreases.

The mechanical properties of the scaffolds were also investigated by DMA analysis after 30 days of soaking (Fig. 13c and d). It was observed that all the scaffolds maintained their original mechanical strength. There were no statistical differences in respect to mechanical properties before and after soaking. The ability of the scaffolds to maintain their mechanical performance during tissue regeneration is very important.

By correlating the previous analyses on the conformation and microstructure of the scaffolds, it is found that the mechanical properties of these scaffolds depended greatly on their conformation and porosity. The crystal conformation obtained is responsible for the water stability, while the decrease in porosity resulted in improved mechanical properties, in both the wet and dry states.

\subsection{Water uptake and degradation-related properties}

The ability to take up fluids from the surrounding medium plays an important role in tissue engineering. As can be seen in Fig. 14a, the water uptake ratio of all the scaffolds reached equilibrium after only $3 \mathrm{~h}$ of immersion in aqueous solutions, and can be maintained for up to 30 days. This result shows that the scaffolds possess a good hydration capability and are able to maintain their structural integrity. The water uptake ratios of the scaffolds decreased with increasing silk fibroin concentration (Fig. 14a). The differences in water uptake can be attributed to the different porosities of the scaffolds. It was observed that for the scaffolds with higher porosity, the water uptake ratio increased. This trend is in agreement with previously reported observations [14].

All the scaffolds maintained their original weights after soaking in aqueous solutions for 30 days (Fig. 14b). From XRD and FTIR data, it was possible to observe that the silk fibroin crystal conformation in the scaffolds is responsible for the stability of the scaffolds during the in vitro degradation test. Furthermore, the morphology of the scaffolds after immersion in ISS for 30 days was assessed by SEM (Fig. 5). It can be seen that there were no differences in the scaffolds' morphology before and after 30 days degradation, which is evidence of their stability.

The stable water uptake ratio, the negligible weight loss and the maintenance of the original morphology of the produced scaffolds during the degradation study are clearly related to the silk fibroin crystal conformation. The differences in the water uptake ratios were related to their varied porosities. These results can provide a valuable reference for the future application of these structures in cartilage and meniscus tissue-engineered scaffolding.

\section{Conclusions}

In this study, an initial physicochemical characterization is presented of silk fibroin scaffolds derived from high-concentration aqueous silk fibroin solution and prepared by combining the saltleaching and freeze-drying methodologies. The results indicate that the developed scaffolds presented silk-II conformation, as confirmed by FTIR and XRD. Morphological study revealed that the scaffolds possessed both macro- and microporous structures, and the morphology varied depending on the initial concentration. Micro-CT analysis further demonstrated that the prepared scaffolds possessed high porosity and interconnectivity, which seemed to decrease with increasing silk fibroin concentration. An opposite 
lar thickness of the trend was exhibited in terms of the trabecular thickness of the
scaffolds. Compressive testing and DMA analysis showed that the mechanical properties of the silk fibroin scaffolds increased dramatically with increasing of silk fibroin concentration. The viscosity properties of silk-10, silk-12 and silk-16 were stable at the testing frequencies. Water uptake data demonstrated that the scaffolds presented a large swelling capability that increased with increasing porosity. It should be highlighted that the prepared scaffolds kept their original structure and morphology, as well as their original mechanical properties, after 30 days of immersion. Therefore, the developed silk fibroin scaffolds are good candidates for use in tissue-engineered scaffolding, namely for cartilage and meniscus regeneration.

This study also opens a new window to preparing load-bearing multifunctional silk fibroin-based scaffolds for other specific tissue engineering applications. Based on the promising physicochemical performance of the developed scaffolds, further in vitro (with cell lines, primary cells) and in vivo studies are envisioned in order to fully evaluate the biological performance of the developed silk scaffolds.

\section{Acknowledgements}

L.-P.Y. acknowledges the Portuguese Foundation for Science and Technology (FCT) for offering him the PhD scholarship (SFRH/BD/ $64717 / 2009$ ). The authors are grateful for the support from the Portuguese Foundation for Science and Technology (FCT) through the Tissue2Tissue Project (PTDC/CTM/105703/2008). The authors are also thankful to Dr. Correlo VM (3B's Research Group) for assistance with the dry status compressive test, and Dr. Silva SS (3B's Research Group) and Dr. Pereira SG (3B's Research Group) for helpful discussion of silk fibroin purification and scaffold preparation.

\section{Appendix A. Supplementary data}

Supplementary data associated with this article can be found, in the online version, at doi:10.1016/j.actbio.2011.09.037.

\section{References}

[1] Langer R, Vacanti JP. Tissue engineering. Science 1993;260(5110):920-6.

[2] Hutmacher DW. Scaffolds in tissue engineering bone and cartilage. Biomaterials 2000;21(24):2529-43.

[3] Ma PX. Scaffolds for tissue fabrication. Mater Today 2004;7(5):30-40.

[4] Yan L, Wang Y, Ren L, Wu G, Caridade SG, Fan J, et al. Genipin-cross-linked collagen/chitosan biomimetic scaffolds for articular cartilage tissue engineering applications. J Biomed Mater Res A 2010;95A(2):465-75.

[5] Puppi D, Chiellini F, Piras AM, Chiellini E. Polymeric materials for bone and cartilage repair. Prog Polym Sci 2010;35(4):403-40.

[6] Oliveira JM, Grech JMR, Leonor IB, Mano JF, Reis RL. Calcium-phosphate derived from mineralized algae for bone tissue engineering applications. Mater Lett 2007;61(16):3495-9.

[7] Oliveira JM, Salgado AJ, Sousa N, Mano JF, Reis RL. Dendrimers and derivatives as a potential therapeutic tool in regenerative medicine strategies - a review. Prog Polym Sci 2010;35(9):1163-94.

[8] Correlo VM, Boesel LF, Bhattacharya M, Mano JF, Neves NM, Reis RL. Hydroxyapatite reinforced chitosan and polyester blends for biomedical applications. Macromol Mater Eng 2005;290(12):1157-65.

[9] Oliveira AL, Malafaya PB, Reis RL. Sodium silicate gel as a precursor for the in vitro nucleation and growth of a bone-like apatite coating in compact and porous polymeric structures. Biomaterials 2003;24(15):2575-84.

[10] Oliveira JM, Rodrigues MT, Silva SS, Malafaya PB, Gomes ME, Viegas CA, et al. Novel hydroxyapatite/chitosan bilayered scaffold for osteochondral tissueengineering applications: scaffold design and its performance when seeded with goat bone marrow stromal cells. Biomaterials 2006;27(36):6123-37.

[11] Altman GH, Diaz F, Jakuba C, Calabro T, Horan RL, Chen J, et al. Silk-based biomaterials. Biomaterials 2003;24(3):401-16.

[12] Vepari C, Kaplan DL. Silk as a biomaterial. Prog Polym Sci 2007;32(89):991-1007.

[13] Murphy AR, Kaplan DL. Biomedical applications of chemically-modified silk fibroin. J Mater Chem 2009;19(36):6443-50.
[14] Kim UJ, Park J, Kim HJ, Wada M, Kaplan DL. Three-dimensional aqueousderived biomaterial scaffolds from silk fibroin. Biomaterials 2005;26(15):2775-85.

[15] Kim U, Park J, Li C, Jin H, Valluzzi R, Kaplan DL. Structure and properties of silk hydrogels. Biomacromolecules 2004:5(3):786-92.

[16] Sofia S, McCarthy MB, Gronowicz G, Kaplan DL. Functionalized silk-based biomaterials for bone formation. J Biomed Mater Res 2001;54(1):139-48.

[17] Wang YZ, Kim HJ, Vunjak-Novakovic G, Kaplan DL. Stem cell-based tissue engineering with silk biomaterials. Biomaterials 2006;27(36):6064-82.

[18] Wang X, Yucel T, Lu Q Hu X, Kaplan DL. Silk nanospheres and microspheres from silk/PVA blend films for drug delivery. Biomaterials 2010;31(6):10251035.

[19] Nazarov R, Jin H, Kaplan DL. Porous 3-D scaffolds from regenerated silk fibroin. Biomacromolecules 2004;5(3):718-26.

[20] Ghanaati S, Orth C, Unger RE, Barbeck M, Webber MJ, Motta A, et al. Finetuning scaffolds for tissue regeneration: effects of formic acid processing on tissue reaction to silk fibroin. J Tissue Eng Regen M 2010;4(6):464-72.

[21] Oliveira AL, Sun L, Kim HJ, Hu X, Rice W, Kluge J, et al. Designing silk-based 3D architectures with controlled lamellar morphology. Tissue Eng PT A 2008;14(5):718-9.

[22] Fuchs S, Motta A, Migliaresi C, Kirkpatrick CJ. Outgrowth endothelial cells isolated and expanded from human peripheral blood progenitor cells as a potential source of autologous cells for endothelialization of silk fibroin biomaterials. Biomaterials 2006;27(31):5399-408.

[23] Meinel L, Fajardo R, Hofmann S, Langer R, Chen J, Snyder B, et al. Silk implants for the healing of critical size bone defects. Bone 2005;37(5):688-98.

[24] Meinel L, Karageorgiou V, Fajardo R, Snyder B, Shinde-Patil V, Zichner L, et al. Bone tissue engineering using human mesenchymal stem cells: effects of scaffold material and medium flow. Ann Biomed Eng 2004;32(1):112-22.

[25] Kundu B, Kundu SC. Osteogenesis of human stem cells in silk biomaterial for regenerative therapy. Prog Polym Sci 2010;35(9):1116-27.

[26] Mandal BB, Kundu SC. Cell proliferation and migration in silk fibroin 3D scaffolds. Biomaterials 2009;30(15):2956-65.

[27] Ghosh S, Parker ST, Wang X, Kaplan DL, Lewis JA. Direct-write assembly of microperiodic silk fibroin scaffolds for tissue engineering applications. Adv Funct Mater 2008;18(13):1883-9.

[28] Makaya K, Terada S, Ohgo K, Asakura T. Comparative study of silk fibroin porous scaffolds derived from salt/water and sucrose/hexafluoroisopropanol in cartilage formation. J Biosci Bioeng 2009;108(1):68-75.

[29] Wang Y, Bella E, Lee CS, Migliaresi C, Pelcastre L, Schwartz Z, et al. The synergistic effects of 3-D silk fibroin matrix scaffold properties and hydrodynamic environment in cartilage tissue engineering. Biomateirals 2010;31(17):4672-81.

[30] Lovett ML, Cannizzaro CM, Vunjak-Novakovic G, Kaplan DL. Gel spinning of silk tubes for tissue engineering. Biomaterials 2008;29(35):4650-7.

[31] Jin H, Kaplan DL. Mechanism of silk processing in insects and spiders. Nature 2003;424(6952):1057-61.

[32] Marolt D, Augst A, Freed LE, Vepari C, Fajardo R, Patel N, et al. Bone and cartilage tissue constructs grown using human bone marrow stromal cells, silk scaffolds and rotating bioreactors. Biomaterials 2006;27(36):6138-49.

[33] Kim HJ, Kim UJ, Leisk GG, Bayan C, Georgakoudi I, Kaplan DL. Bone regeneration on macroporous aqueous-derived silk 3-D scaffolds. Macromol Biosci 2007;7(5):643-55.

[34] Collins AM, Skaer NJV, Gheysens T, Knight D, Bertram C, Roach HI, et al. Bonelike resorbable silk-based scaffolds for load-bearing osteoregenerative applications. Adv Mater 2009;21(1):75-8.

[35] Rajkhowa R, Gil ES, Kluge J, Numata K, Wang L, Wang X, et al. Reinforcing silk scaffolds with silk particles. Macromol Biosci 2010;10(6):599-611.

[36] Pinho ED, Martins A, Araúo JV, Reis RL, Neves NM. Degradable particulate composite reinforced with nanofibres for biomedical applications. Acta Biomater 2009;5(4):1104-14.

[37] Asakura T, Kuzuhara A, Tabeta R, Saitô H. Conformation characterization of Bombyx mori silk fibroin in the solid state by high-frequency ${ }^{13} \mathrm{C}$ cross polarization-magic angle spinning NMR, X-ray diffraction, and infra spectroscopy. Macromolecules 1985;18(10):1841-5.

[38] Ishida M, Asakura T, Yoko M, Saitô H. Solvent- and mechanical-treatmentinduced conformational transition of silk fibroins studied by high-resolution solid-state ${ }^{13} \mathrm{C}$ NMR spectroscopy. Macromolecules 1990;23(1):88-94.

[39] Kratky O, Schauenstein E, Sekora A. An unstable lattice in silk fibroin. Nature 1950;165(4191):319-20.

[40] Wilson D, Valluzzi R, Kaplan D. Conformational transitions in model silk peptides. Biophys J 2000;78(5):2690-701.

[41] Zhao C, Yao j, Masuda H, Kishore R, Asakura T. Structural characterization and artificial fiber formation of Bombyx mori silk fibroin in hexafluoro-iso-propanol solvent system. Biopolymers 2003;69(2):253-9.

[42] Drummy LF, Phillips DM, Stone MO, Farmer BL, Naik RR. Thermally induced $\alpha-$ helix to $\beta$-sheet transition in regenerated silk fibers and films. Biomacromolecules 2005;6(6):3328-33.

[43] Lu Q Hu X, Wang XQ Kluge J, Lu SZ, Cebe P, et al. Water-insoluble silk films with silk-I structure. Acta Biomater 2010;6(4):1380-7.

[44] Jin HJ, Park J, Karageorgiou V, Kim UJ, Valluzzi R, Cebe P, et al. Water-stable silk films with reduced $\beta$-sheet content. Adv Funct Mater 2005;15(8):1241-7.

[45] Tamada Yasushi. New process to form a silk fibroin porous 3-D structure. Biomacromolecules 2005;6(6):3100-6.

[46] Chen X, Shao ZZ, Knight DP, Vollrath F. Conformation transition kinetics of Bombyx mori silk protein. Proteins 2007;68(1):223-31. 
[47] Demura M, Asakura T, Kuroo T. Immobilization of biocatalysts with Bombyx mori silk fibroin by several kinds of physical treatment and its application to glucose sensors. Biosensors 1989;4(6):361-72.

[48] Karageorgiou V, Kaplan D. Porosity of 3D biomaterial scaffolds and osteogenesis. Biomaterials 2005;26(27):5474-91.

[49] Oliveira AL, Malafaya PB, Costa SA, Sousa RA, Reis RL. Micro-computed tomography $(\mu-C T)$ as a potential tool to assess the effect of dynamic coating routes on the formation of biomimetic apatite layers on 3D-plotted biodegradable polymeric scaffolds. J Mater Sci-Mater M 2007;18(2):211-23.

[50] Ho ST, Hutmacher DW. A comparison of micro CT with other techniques used in the characterization of scaffolds. Biomaterials 2006;27(18):1362-76.
[51] Chia HN, Hull ML. Compressive moduli of the human medial meniscus in the axial and radial directions at equilibrium and at a physiological strain rate. J Orthopaed Res 2008;26(7):951-6.

[52] Lai JH, Levenston ME. Meniscus and cartilage exhibit distinct intra-tissue strain distributions under unconfined compression. Osteoarthr Cartilage 2010;18(10):1291-9.

[53] Moutos FT, Freed LE, Guilak F. A biomimetic three-dimensional woven composite scaffold for functional tissue engineering of cartilage. Nat Mater 2007;6(2):162-7. 